\title{
Functionalization of P3HT with Various Mono- and Multidentate Anchor Groups
}

\author{
Florian Menk, ${ }^{\#}$ Ana Fokina, ${ }^{\#}$ Bernd Oschmann,, Tobias A. Bauer, ${ }^{\#}$ Yannick Nyquist, \\ Lydia Braun, Jonathan Kiehl and Rudolf Zentel*
}

\author{
Institute for Organic Chemistry, Johannes Gutenberg University, \\ Duesbergweg 10-14, 55128 Mainz, Germany
}

\begin{abstract}
Due to its favorable optoelectronic properties and the accessibility via Grignard metathesis (GRIM) polymerization, poly(3-hexylthiophene) (P3HT) is one of the most applied conjugated polymers. The 'living' nature of GRIM polymerization enables the modification of the polymer and the installation of desired properties. In the present study, two versatile approaches for the synthesis of anchor group-modified P3HT have been developed, which enable the functionalization of various inorganic nanoparticles. Depending on the polymerization conditions, mono- and bifunctional ethynyl-terminated P3HT or solely monofunctionalized aldehyde-terminated P3HT was synthesized. Afterwards, the quantitative introduction of amine, mono- and multidentate disulfide and catechol anchor groups was performed by copper-catalyzed 1,3-dipolar cycloaddition or via imine formation reactions. The influence of the polymeric ligand structure on the functionalization of nanoparticles was then investigated for CdSe@ ZnS quantum dots and $\mathrm{TiO}_{2}$ nanorods by transmission electron microscopy (TEM) and infrared (IR) spectroscopy.
\end{abstract}

Keywords: click chemistry, conjugated polymers, P3HT, GRIM, hybrid nanocomposites

\section{Introduction}

The design of conjugated polymers with favorable optoelectronic properties has been the subject of research for several decades. Early on, the application of these organic semiconductors in organic solar cells, light-emitting diodes, optical waveguides and lasers has been envisioned and tested. ${ }^{1}$ Besides ring-opening metathesis polymerization (ROMP) and cyclopolymerization, Grignard metathesis (GRIM) polymerization represents one of the few 'living' polymerization techniques capable of synthesizing conjugated polymers. ${ }^{2}$ First discovered by McCullough et al. ${ }^{2}$ in 1993, GRIM polymerization enables the facile synthesis of conjugated polymers such as poly(3-alkylthiophenes) (P3ATs) with a high degree of regioregularity. ${ }^{3}$ In addition, the synthesis of block copolymers and the incorporation of well-defined polymer end groups is permitted. ${ }^{4,5}$ As a result, P3ATs obtained from GRIM polymerization have been established as hole-transporting organic semiconductors and are among the most applied conjugated polymers. ${ }^{2,6}$ For the formation of hybrid optoelectronic devices P3ATs

*e-mail: zentel@uni-mainz.de

\#These authors contributed equally to this work.

This paper is part of the PubliSBQ Special Issue "IUPAC-2017" (http://publi.sbq.org.br/). have also been combined with their inorganic analogs, e.g. $\mathrm{TiO}_{2}$ or $\mathrm{CdSe}$, as this approach enables the utilization of outstanding electron- and hole-transporting materials. While the concept of hybrid solar cells or light-emitting diodes appears to be superior to common organic solar cells, a major task is to enable efficient interaction of polymers and inorganic nanoparticles, avoiding microphase-separation typically occurring for polymer/ nanoparticle blends, as this lowers the overall device performance. ${ }^{6}$ Consequently and from a chemical aspect, functional end groups facilitating an effective interaction of conjugated polymers with inorganic nanoparticles are desirable for hybrid optoelectronic devices. ${ }^{7,8}$ This allows a homogeneous dispersion of inorganic and organic materials as well as an intimate molecular contact of both materials, which is beneficial for the preparation of photovoltaic devices from inorganic and organic materials and for the preparation of hybrid QD-LEDs (quantum dot light-emitting diodes). ${ }^{7,-11}$ The advantageous effect of anchor groups on the performance of hybrid solar cells was first demonstrated by Liu et al. ${ }^{12}$ in 2004. They studied hybrid solar cells composed of poly(3-hexylthiophene) (P3HT)/CdSe QDs and achieved an improved device performance upon the incorporation of an amino anchor group at the P3HT chain end. ${ }^{12}$ Moreover, recent advances in the field of hybrid solar 
cells emphasize the importance of ligand exchange steps to substitute the initial, typically insulating surfactants on the QD surface. The application of appropriate ligand exchange procedures, generally, leads to improved efficiencies and, thus, enables the fabrication of hybrid solar cells exhibiting efficiencies of 4.5 to $5.5 \% .{ }^{13}$ Furthermore, several studies have been carried out with the aim to investigate the influence of various ligands on different aspects such as the film morphology and the charge separation at the organic/ inorganic interface. ${ }^{14,15}$ As the incorporation of different and multidentate anchoring end groups remains a challenge in the case of conjugated polymers, most studies, so far, mainly focused on ligand exchange using small molecules such as pyridine or 1,2-ethanedithiol. ${ }^{16}$ Despite these findings, literature demonstrates that the incorporation of anchor groups at the polymer chain end can lead to enhanced efficiencies. ${ }^{12,17}$ Moreover, the influence of anchor groups at the polymer chain end might differ from the effects observed for small molecules exhibiting the same functional groups. Very recently, the advantage of chemical coupling between the inorganic and organic part was successfully demonstrated for QD-LEDs. ${ }^{18}$ Therefore, techniques which facilitate the incorporation of suitable anchor groups at the chain end of conjugated polymers such as $\mathrm{P} 3 \mathrm{HT}$ are required.

In this study, we describe the incorporation of various mono- and multidentate anchor groups at the polymer chain end of P3HT for the functionalization of chalcogenide nanoparticles via two approaches (see Figure 1). Both approaches in Figure 1 lead to monofunctionalized P3HT, but with a different selectivity. While approach 1 (upper line) results in the formation of about $15 \%$ bifunctional polymers, they contain the functional group at both chain end. This has to be kept in mind as these bifunctional polymers have the possibility to adsorb to two nanoparticles, which might lead to some aggregate formation at high concentrations. On the contrary, following approach 2
(Figure 1) solely monofunctional polymer chains are obtained. Since the morphology of nanocomposite films depends on the stability of the polymer coating at the nanoparticle surface, the stability of the coating can be addressed by the number of binding sites and the affinity of the functional groups toward the respective inorganic surface. ${ }^{7,19}$ Therefore, we incorporated both, mono- as well as multidentate anchor groups with varying functionalities (i.e., catechol, lipoic acid, amine and trithiocarbonate) ${ }^{20}$ As the device performance strongly depends on the functional group interacting with the inorganic nanoparticles, the ability to incorporate different functional groups following the same polymer synthesis approach is of special interest for studies with the aim to investigate the influence of various functional groups on the device performance. ${ }^{14}$

Finally, P3HT polymer chains modified with amine and disulfide functionalities were tested as anchor groups for chalcogenide nanoparticles, while $\mathrm{TiO}_{2}$ nanoparticles have been functionalized with P3HT carrying catechol anchor groups.

\section{Experimental}

\section{Materials and characterization}

All commercially available chemicals were purchased from Alfa Aesar, Acros Organics, Fluka, Sigma-Aldrich, or Tokyo Chemical Industry and used without further purification unless otherwise noted. Anhydrous THF (tetrahydrofuran) was freshly distilled from sodium under a dry argon atmosphere. All reactions were carried out under dry nitrogen or argon atmospheres using standard Schlenk-techniques. Molecular weights $\left(M_{n}\right)$ of all synthesized polymers were determined by gel permeation chromatography (GPC) with a concentration of approximately $1.2 \mathrm{mg} \mathrm{mL}^{-1}$ in THF with polystyrene

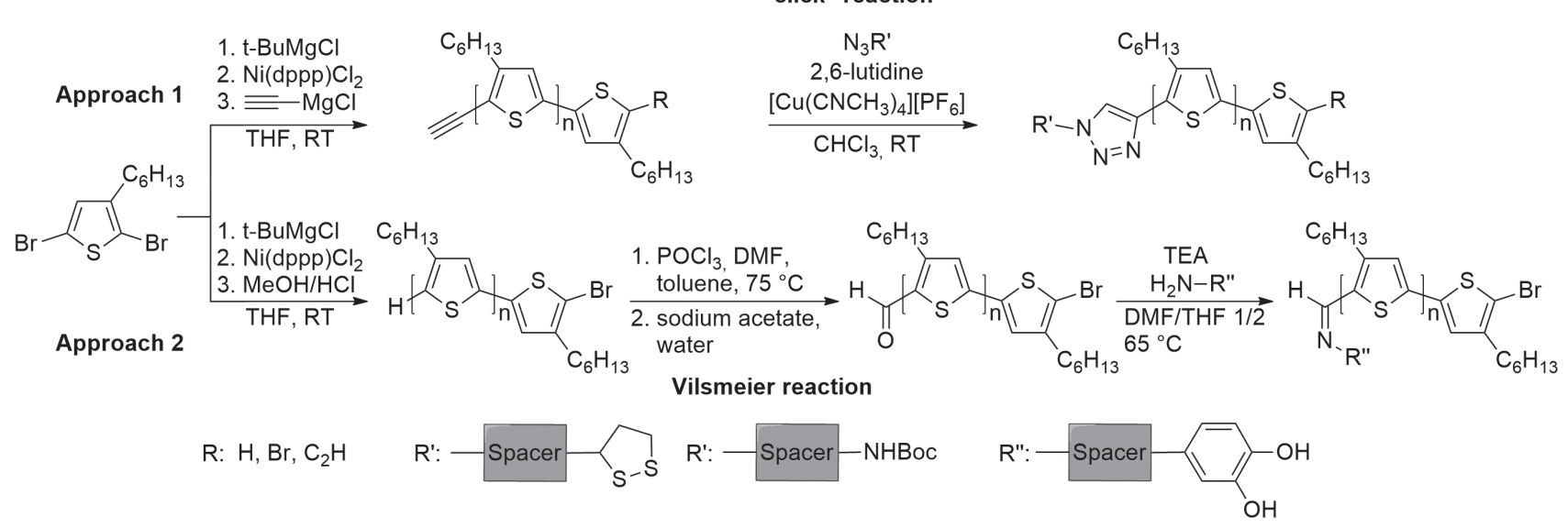

Figure 1. General reaction scheme illustrating the two approaches exploited in the present study. 
as external and toluene as internal standard. Azides 1-5 (an illustration of compounds $\mathbf{1 - 5}$ can be found in the Supplementary Information (SI), Figure S1) and pentafluorophenyl 4-vinylbenzoate (PFP4VB) were synthesized according to literature procedures. ${ }^{20-22}$ Syntheses of ethynyl-terminated and aldehyde-terminated P3HT were conducted following modifications of established literature procedures. ${ }^{23,24}{ }^{1} \mathrm{H},{ }^{19} \mathrm{~F}$ and ${ }^{13} \mathrm{C}$ NMR (nuclear magnetic resonance) spectra were acquired on a Bruker ARX 400 spectrometer at a Lamor frequency of 400, 376 and $101 \mathrm{MHz}$, respectively. Fourier transform infrared (FTIR) spectra were performed on a Vector 22 ATR-FTIR-spectrometer made by Bruker. UV-Vis spectra were obtained by Jasco Inc. UV-Vis Spectrophotometer V-630. Transmission electron microscopy (TEM) images of P3HT coated CdSe@ZnS QDs were recorded with JEOL ARM $200 \mathrm{~F}$ operating at $20 \mathrm{kV}$ or P3HT coated $\mathrm{TiO}_{2}$ particles were characterized by TEM using a Philips EM 420. TEM samples were prepared by drop casting a dispersion of the QDs in chloroform on a standard carboncoated copper grid. MALDI-TOF MS (matrix-assisted laser desorption ionization time-of-flight mass spectrometry) were recorded using a Bruker-reflex-TOF (FM-0405) and a nitrogen laser (Laser Science, Inc., VSL-337ND-S, wavelength $=337 \mathrm{~nm}$ ). The spectra were collected in reflector mode, calibration was done against $\mathrm{C} 60 / \mathrm{C} 70$ and 2,2 '5,2"-terthiophene was used as matrix for all samples.

General procedure for end group modifications via 1,3-dipolar cycloaddition

Azides were installed as polymer end groups according to a modified literature procedure. ${ }^{25}$ Under a dry nitrogen atmosphere ethynyl-terminated P3HT (150 mg, $0.029 \mathrm{mmol}$, $\mathrm{M}_{\mathrm{n}}$ (GPC) ca. $5200 \mathrm{~g} \mathrm{~mol}^{-1}, 1$ equiv.) was dissolved in $20 \mathrm{~mL}$ of dry chloroform. Subsequently, the respective azide (0.288 mmol, 10 equiv.), 2,6-lutidine (309 mg, $0.34 \mathrm{~mL}$, $2.88 \mathrm{mmol}, 100$ equiv.) and $\left[\mathrm{Cu}\left(\mathrm{NCCH}_{3}\right)_{4}\right]\left[\mathrm{PF}_{6}\right](54 \mathrm{mg}$, $0.144 \mathrm{mmol}, 5$ equiv.) were added. The reaction mixture was stirred at room temperature for $64 \mathrm{~h}$. The reaction mixture was concentrated under reduced pressure and P3HT was precipitated in methanol. After dissolving the modified P3HT in DCM (dichloromethane) and precipitation in methanol three times, the product was collected as a violet solid.

\section{P2a}

${ }^{1} \mathrm{H}$ NMR (400 MHz, $\left.\mathrm{CDCl}_{3}\right) \delta 7.73$ (s, $1 \mathrm{H}$, triazole), 6.81-7.03 (m, 20H, Ar), 5.77 (t, J 6.2 Hz, 1H, NH), 4.49 (t, J $6.5 \mathrm{~Hz}, 2 \mathrm{H}$, triazole- $\left.\mathrm{CH}_{2}\right), 3.52-3.59(\mathrm{~m}, 1 \mathrm{H}, \mathrm{S}-\mathrm{CH})$, 3.33 (q, J $6.2 \mathrm{~Hz}, 2 \mathrm{H}, \mathrm{NH}-\mathrm{CH}_{2}$ ), 3.07-3.19 (m, 2H,
S-CHH), 2.53-2.82 (m, 40H, Ar- $\left.\mathrm{CH}_{2}\right), 2.40-2.48$ (m, $1 \mathrm{H}, \mathrm{S}-\mathrm{CH}_{2}-\mathrm{CHH}$ ), 2.14-2.21 (m, 4H, $\mathrm{CH}_{2}$ ), 1.85-1.93 (m, $\left.1 \mathrm{H}, \mathrm{S}-\mathrm{CH}_{2}-\mathrm{CHH}\right), 1.26-1.74\left(\mathrm{~m}, 166 \mathrm{H}, \mathrm{CH}_{2}\right), 0.87-0.94$ (m, 60H, $\mathrm{CH}_{3}$ ).

\section{P2b}

${ }^{1} \mathrm{HNMR}\left(400 \mathrm{MHz}, \mathrm{CDCl}_{3}\right) \delta 7.64(\mathrm{~s}, 1 \mathrm{H}$, triazole), 6.817.02 (m, 20H, Ar), 6.52 (t, J 6.3 Hz, 2H, NH), 4.80-4.85 (m, $1 \mathrm{H}, \mathrm{O}-\mathrm{CH}), 4.44\left(\mathrm{t}, J 6.8 \mathrm{~Hz}, 2 \mathrm{H}\right.$, triazole- $\left.\mathrm{CH}_{2}\right), 3.51-3.58$ (m, 2H, S-CH), 3.28-3.34 (m, 4H, NH-CH $), 3.06-3.19$ (m, $4 \mathrm{H}, \mathrm{S}-\mathrm{CHH}$ ), 2.52-2.82 (m, 40H, $\mathrm{Ar}-\mathrm{CH}_{2}$ ), 2.40-2.48 (m, $\left.2 \mathrm{H}, \mathrm{S}-\mathrm{CH}_{2}-\mathrm{CHH}\right), 2.33$ (t, J 7.2 Hz, $2 \mathrm{H}, \mathrm{O}=\mathrm{C}-\mathrm{CH}_{2}$ ), 2.26 (t, $\left.J 7.5 \mathrm{~Hz}, 4 \mathrm{H}, \mathrm{O}=\mathrm{C}-\mathrm{CH}_{2}\right), 2.00(\mathrm{p}, J 7.2 \mathrm{~Hz}, 2 \mathrm{H}$, triazole$\mathrm{CH}_{2}-\mathrm{CH}_{2}$ ), $1.85-1.93$ (m, 2H, S- $\left.\mathrm{CH}_{2}-\mathrm{CHH}\right), 1.22-1.74$ (m, $\left.176 \mathrm{H}, \mathrm{CH}_{2}\right), 0.84-0.95\left(\mathrm{~m}, 60 \mathrm{H}, \mathrm{CH}_{3}\right)$.

\section{P2c}

${ }^{1} \mathrm{H}$ NMR $\left(400 \mathrm{MHz}, \mathrm{CDCl}_{3}\right) \delta 7.64(\mathrm{~s}, 1 \mathrm{H}$, triazole), 6.81-7.01 (m, 20H, Ar), 6.49 (br, 1H, NH), 4.38-4.47 (m, $8 \mathrm{H}, \mathrm{O}-\mathrm{CH}_{2}+$ triazole- $\left.\mathrm{CH}_{2}\right), 3.52-3.57(\mathrm{~m}, 3 \mathrm{H}, \mathrm{S}-\mathrm{CH})$, 3.06-3.21 (m, 6H, S-CHH), 2.54-2.82 (m, 40H, $\mathrm{Ar}-\mathrm{CH}_{2}$ ), 2.42-2.50 (m, 3H, S-CH $-\mathrm{CHH}), 2.36(\mathrm{t}, J 7.3 \mathrm{~Hz}$, $\left.6 \mathrm{H}, \mathrm{O}=\mathrm{C}-\mathrm{CH}_{2}\right), 2.16-2.28\left(\mathrm{~m}, 4 \mathrm{H}, \mathrm{O}=\mathrm{C}-\mathrm{CH}_{2}+\mathrm{CH}_{2}\right)$, $1.98-2.03\left(\mathrm{~m}, 2 \mathrm{H}\right.$, triazole- $\left.\mathrm{CH}_{2}-\mathrm{CH}_{2}\right), 1.87-1.95(\mathrm{~m}, 3 \mathrm{H}$, S- $\left.\mathrm{CH}_{2}-\mathrm{CHH}\right), 1.22-1.74\left(\mathrm{~m}, 180 \mathrm{H}, \mathrm{CH}_{2}\right), 0.85-0.95$ (m, $60 \mathrm{H}, \mathrm{CH}_{3}$ ).

\section{P2d}

${ }^{1} \mathrm{H}$ NMR $\left(400 \mathrm{MHz}, \mathrm{CDCl}_{3}\right) \delta 7.77$ (s, $1 \mathrm{H}$, triazole), 6.81-7.01 (m, 17H, Ar), 4.76 (br, 1H, NH), 4.49 (t, J6.7 Hz, $2 \mathrm{H}$, triazole- $\left.\mathrm{CH}_{2}\right), 3.20\left(\mathrm{q}, J 6.4 \mathrm{~Hz}, 2 \mathrm{H}, \mathrm{NH}-\mathrm{CH}_{2}\right.$ ), 2.51-2.83 (m, 34H, Ar- $\left.\mathrm{CH}_{2}\right), 2.14$ (p, J $6.4 \mathrm{~Hz}, 2 \mathrm{H}, \mathrm{CH}_{2}$ ), $1.25-1.74+1.45\left(\mathrm{~m}+\mathrm{s}, 145 \mathrm{H}, \mathrm{CH}_{2}+t-\mathrm{Bu}\right), 0.83-0.93$ $\left(\mathrm{m}, 51 \mathrm{H}, \mathrm{CH}_{3}\right.$ ). Note: polymer $\mathbf{P 2 d}$ was synthesized from ethynyl-terminated P3HT with degree of polymerization (DP) ca. 17 (P1b).

\section{P2e}

${ }^{1} \mathrm{H}$ NMR $\left(400 \mathrm{MHz}, \mathrm{CDCl}_{3}\right) \delta 7.67(\mathrm{~s}, 1 \mathrm{H}$, triazole), 6.80-7.03 $(\mathrm{m}, 21 \mathrm{H}, \mathrm{Ar}), 4.46\left(\mathrm{t}, 2 \mathrm{H}\right.$, triazole- $\left.\mathrm{CH}_{2}\right), 4.19$ $\left(\mathrm{t}, 2 \mathrm{H}, \mathrm{COO}-\mathrm{CH}_{2}\right), 3.28(\mathrm{~m}, 2 \mathrm{H}$, chain transfer agent (CTA)- $\left.\mathrm{CH}_{2}\right), 2.50-2.85\left(\mathrm{~m}, 42 \mathrm{H}, \mathrm{Ar}-\mathrm{CH}_{2}\right), 2.32(\mathrm{t}, 2 \mathrm{H}$, $\left.\mathrm{CH}_{2}\right), 1.05-1.75\left(\mathrm{~m}, 168, \mathrm{CH}_{2}\right), 0.88-0.93\left(\mathrm{~m}, 63 \mathrm{H}, \mathrm{CH}_{3}\right)$.

\section{Deprotection of polymer P2d (synthesis of polymer P3)}

Polymer P2d (250 mg, $0.063 \mathrm{mmol}, \mathrm{M}_{\mathrm{n}}(\mathrm{GPC})$ ca. $4000 \mathrm{~g} \mathrm{~mol}^{-1}, 1$ equiv.) was dissolved in $6.5 \mathrm{~mL}$ of DCM. Trifluoroacetic acid $(1.6 \mathrm{~mL})$ was added and the reaction mixture was stirred at room temperature for $1 \mathrm{~h}$. Then, the $\mathrm{pH}$ was adjusted to a value of $12 \mathrm{using} 10 \%$ aqueous sodium 
carbonate solution and the reaction mixture was extracted three times with chloroform. The combined organic extracts were dried over $\mathrm{MgSO}_{4}$, filtered and the solvent was removed under reduced pressure. The residue was purified by redissolving in a small amount of chloroform and precipitation in methanol for three times. Further purification was achieved by column chromatography using an $8 / 1$ eluent system of chloroform $/ n$-hexane. The product was obtained as a violet solid in $40 \%$ yield.

${ }^{1} \mathrm{H}$ NMR (400 MHz, $\left.\mathrm{CDCl}_{3}\right) \delta 7.70(\mathrm{~s}, 1 \mathrm{H}$, triazole), 6.82-7.03 (m, 17H, Ar), 5.35 (br, $\left.2 \mathrm{H}, \mathrm{NH}_{2}\right), 4.52(\mathrm{t}$, $J 6.4 \mathrm{~Hz}, 2 \mathrm{H}$, triazole- $\left.\mathrm{CH}_{2}\right), 3.45$ (q, J $6.4 \mathrm{~Hz}, 2 \mathrm{H}$, $\left.\mathrm{NH}-\mathrm{CH}_{2}\right), 2.53-2.84\left(\mathrm{~m}, 34 \mathrm{H}, \mathrm{Ar}-\mathrm{CH}_{2}\right), 2.32-2.39(\mathrm{~m}, 2 \mathrm{H}$, $\mathrm{CH}_{2}$ ), 1.23-1.74 (m, 136H, $\mathrm{CH}_{2}$ ), 0.83-0.93 (m, 51H, $\mathrm{CH}_{3}$ ). Note: polymer $\mathbf{P 3}$ was synthesized from ethynyl-terminated P3HT with DP ca. 17 (P2d).

\section{Synthesis of $\mathbf{P} \mathbf{4 b}$}

PFP4VB (231.4 $\mathrm{mg}, 0.42 \mathrm{mmol}, 25$ equiv.), the macro-CTA (P2e) (75.0 mg, $0.017 \mathrm{mmol}, \mathrm{M}_{\mathrm{n}}(\mathrm{NMR})$ ca. $4400 \mathrm{~g} \mathrm{~mol}^{-1}$, 1 equiv.), and AIBN (azobisisobutyronitrile, $0.28 \mathrm{mg}, 0.0017 \mathrm{mmol}, 0.2$ equiv.) were dissolved in $2 \mathrm{~mL}$ $o$-dichlorobenzene followed by three freeze-pump-thaw cycles. The reaction mixture was stirred for $48 \mathrm{~h}$ at $70{ }^{\circ} \mathrm{C}$. The reaction was stopped by quenching in methanol and the product $\mathbf{P 4 a}$ was further purified by solving and precipitating two more times. The yield was $85 \%$.

${ }^{1} \mathrm{H}$ NMR $\left(400 \mathrm{MHz}, \mathrm{CDCl}_{3}\right) \delta 7.70-8.25(\mathrm{~m}, 10 \mathrm{H}, \mathrm{Ar}$ of PFP4VB), 7.60 (s, 1H, triazole), 6.60-7.20 (m, 30H, $\mathrm{Ar}$ of P3HT and PFP4VP), $4.39\left(\mathrm{~m}, 2 \mathrm{H}\right.$, triazole- $\left.\mathrm{CH}_{2}\right), 3.77$ (m, 2H, COO- $\mathrm{CH}_{2}$ ), 3.27 (m, 2H, CTA- $\left.\mathrm{CH}_{2}\right), 2.50-2.85$ (m, 40H, Ar- $\mathrm{CH}_{2}$ ), 2.13 (m, 2H, $\mathrm{CH}_{2}$ ), 1.05-1.5 (m, 160, $\left.\mathrm{CH}_{2}\right), 0.88-0.93\left(\mathrm{~m}, 60 \mathrm{H}, \mathrm{CH}_{3}\right) ;{ }^{19} \mathrm{~F}$ NMR $(376 \mathrm{MHz}$, $\left.\mathrm{CDCl}_{3}\right) \delta-154.3(\mathrm{~m}, 2 \mathrm{~F}$, ortho-F), -157.9 (m, 1F, para-F), -163.3 (m, 2F, meta-F); FTIR (ATR) v / $\mathrm{cm}^{-1} 2925$ (CH), $1760(\mathrm{C}=\mathrm{O}), 1519$ (Ar-F), 1240, 1044 (aromatic band), $1013,819$.

P(3HT- $b$-PFP4VB) (27 mg, 0.0034 mmol, 1 equiv.) was dissolved in $1.4 \mathrm{~mL}$ THF and a solution of dopamine hydrochloride (12.7 mg, $0.068 \mathrm{mmol}, 20$ equiv.) in $0.6 \mathrm{~mL}$ DMF ( $N, N$-dimethylformamide) was added. Triethylamine ( $2.4 \mathrm{~mL}, 0.068 \mathrm{mmol}, 20$ equiv.) was added as well. The reaction mixture was stirred at room temperature overnight.

${ }^{1} \mathrm{H}$ NMR (400 MHz, $\mathrm{CDCl}_{3}$ ) $\delta 7.67$ (s, triazole), 6.68-7.28 (m, Ar of P3HT, PFP4VB and dopamine), $4.32\left(\mathrm{~m}\right.$, triazole- $\left.\mathrm{CH}_{2}\right), 4.19\left(\mathrm{~m}, \mathrm{COO}-\mathrm{CH}_{2}\right), 3.72(\mathrm{~m}$, CTA- $\left.\mathrm{CH}_{2}\right), 2.80\left(\mathrm{~m}, \mathrm{Ar}-\mathrm{CH}_{2}\right), 1.5-1.0\left(\mathrm{~m}, \mathrm{CH}_{2}\right), 0.92-0.88$ (b, $\mathrm{CH}_{3}$ ). Note: integration is due to the overlap of several aromatic hydrogens not reasonable. FTIR (ATR) $\mathrm{v} / \mathrm{cm}^{-1}$ $3248(\mathrm{O}-\mathrm{H}), 1734(\mathrm{C}=\mathrm{O})$.

\section{Synthesis of dopamine-P3HT (P5c)}

The formylation of hydrogen terminated P3HT (P5a) (120 mg, 0.022 mmol, $\mathrm{M}_{\mathrm{n}}$ (GPC) ca. $5400 \mathrm{~g} \mathrm{~mol}^{-1}, 1$ equiv.) was conducted following a reported method by a Vilsmeier reaction. ${ }^{23}$ Briefly, $\mathrm{P} 3 \mathrm{HT}$ was dissolved in toluene $(30 \mathrm{~mL})$ under an argon atmosphere. DMF $(0.36 \mathrm{~mL}, 4.66 \mathrm{mmol}$, 212 equiv. ) and $\mathrm{POCl}_{3}(0.25 \mathrm{~mL}, 2.7 \mathrm{mmol}, 122$ equiv. $)$ were added. The reaction mixture was stirred for $50 \mathrm{~h}$ at $75^{\circ} \mathrm{C}$. After the completion of the reaction saturated aqueous sodium acetate solution was added and stirred for further $30 \mathrm{~min}$. Thereafter, the reaction mixture was precipitated in methanol and dried under reduced pressure. The product (P5b) was dissolved in chloroform and precipitated two more times in methanol. The yield was $87 \%$.

$\left.{ }^{1} \mathrm{H} \mathrm{NMR} \mathrm{(400} \mathrm{MHz,} \mathrm{CDCl}_{3}\right) \delta 10.02(\mathrm{~s}, 1 \mathrm{H}$, aldehyde-H), 6.91-7.09 (m, 26H, Ar), 2.95 (t, 2H, Ar- $\mathrm{CH}_{2}$ in ortho-position to aldehyde group), 2.60-3.05 (m, 52H, Ar- $\mathrm{CH}_{2}$ ), 1.15-1.80 (m, 208H, $\left.\mathrm{CH}_{2}\right), 0.84-0.96$ (m, 78H, $\mathrm{CH}_{3}$ ); FTIR (ATR) v / cm ${ }^{-1} 2924$ (w, CH), 1649 (s, C=O), 1443 (w, aromatic ring), $820(\mathrm{w})$.

Dopamine was introduced by aminolysis of the carbonyl group. Therefore, P5b (38 mg, 9 mmol, $\mathbf{M}_{\mathrm{n}}(\mathrm{NMR})$ ca. $4200 \mathrm{~g} \mathrm{~mol}^{-1}, 1$ equiv.) was dissolved in dried THF (1 mL) and a solution of dopamine hydrochloride $(25.7 \mathrm{mg}$, $135 \mathrm{mmol}, 15$ equiv.), triethylamine $(17 \mu \mathrm{L}, 135 \mathrm{mmol}$, 15 equiv.) in DMF ( $1 \mathrm{~mL}$ ) was added. The reaction mixture was stirred at $65{ }^{\circ} \mathrm{C}$ overnight. The final product, polymer P5c, was purified by precipitation in methanol. The yield was $76 \%$.

${ }^{1} \mathrm{H}$ NMR (400 MHz, $\left.\mathrm{CDCl}_{3}\right) \delta 8.22(\mathrm{~s}, 1 \mathrm{H}$, imine $\mathrm{H})$, 6.91-7.09 (m, 31H, Ar), 6.50-6.85 (m, 3H, Ar of dopamine), 2.70-2.90 (m, 62H, Ar- $\left.\mathrm{CH}_{2}\right), 1.15-1.80\left(\mathrm{~m}, 248 \mathrm{H}, \mathrm{CH}_{2}\right)$, 0.84-0.96 (m, 93H, $\mathrm{CH}_{3}$ ); FTIR (ATR) v / cm ${ }^{-1} 2924(\mathrm{CH})$, $1654(\mathrm{C}=\mathrm{C}), 1617(\mathrm{C}=\mathrm{N}), 1453$ (aromatic ring), 820.

\section{Functionalization of inorganic particles}

10 mg of CdSe@ZnS nanoparticles were dispersed in $1 \mathrm{~mL}$ of chloroform and an argon atmosphere was applied. While the dispersion was ultrasonicated, $10 \mathrm{mg}$ of the respective polymer dissolved in $1 \mathrm{~mL}$ of chloroform were added. The mixture was then stirred at $40{ }^{\circ} \mathrm{C}$ overnight. Unfunctionalized QDs were removed via precipitation in $n$-hexane and redispersion in chloroform (two times).

$\mathrm{TiO}_{2}$ particles were synthesized following a method previously reported. ${ }^{26} \mathrm{TiO}_{2}$ particles were dispersed in chloroform with a concentration of $10 \mathrm{mg} \mathrm{mL}^{-1}$. Polymer P4b or P5c were each dissolved in chloroform with a final polymer concentration of $5 \mathrm{mg} \mathrm{mL}^{-1}$. The polymer solution was added to the particle dispersion 
and ultrasonicated under argon for $30 \mathrm{~min}$. Afterwards the mixture was stirred at $40{ }^{\circ} \mathrm{C}$ overnight. To remove unbound polymer, the functionalized nanoparticles were sedimented by centrifugation at 13000 rotations per min, the supernatant was removed and the particles were again dispersed in chloroform. This purification protocol was repeated for three times.

\section{Results and Discussion}

In this study (i) amine-, (ii) liponamide- and (iii) catechol-based anchor groups have been selected to enable an efficient functionalization of the most applied inorganic nanoparticles (e.g. CdSe @ $\mathrm{ZnS}$ and $\mathrm{TiO}_{2}$ ) with P3HT.

In the first approach, ethynyl-terminated P3HT was prepared by a GRIM polymerization, terminated with ethynylmagnesium bromide. In accordance with the literature, ${ }^{24} 85 \%$ mono- and $15 \%$ bifunctional P3HT were obtained. Both mono- and bifunctional products were detected by MALDI-TOF MS (see Figure S2, SI section). In the next step, various anchoring groups have been introduced via copper catalyzed azide-alkyne Huisgen cycloaddition ("click" reaction), as illustrated in Figure 2.

Lipoic acid which is known to facilitate ligand exchange with sulfidic nanoparticles like CdSe@ZnS QDs was incorporated as anchoring end group. ${ }^{27}$ In a one-step procedure, $N$-3-azidopropyl liponamide (for the structure of the various liponamides see Figure S1 in the SI section) was reacted with ethynyl-terminated P3HT (P1) in a Huisgen cycloaddition yielding mono liponamide-modified P3HT (P2a). The successful end group modification was verified using ${ }^{1} \mathrm{H}$ NMR spectroscopy and MALDI-TOF MS (see Figure 3). Notably, the singlet of the alkyne proton (3.53 ppm) vanished upon reaction whereas the single triazole-proton appeared at $7.73 \mathrm{ppm}$ (in $\mathrm{CDCl}_{3}$ ). Moreover, characteristic signals, such as the triplet of the methylene group adjacent to the azide moiety, which was shifted from 3.37 to 4.49 ppm upon successful triazole formation, could be assigned to the lipoic acid end group.

In more detail, MALDI-TOF MS revealed the coexistence of three polymer-species, as displayed in Figure 3b. The concomitance of monofunctional P3HT (carrying a proton or bromine at the alpha end) and bifunctional P3HT originates from the coexistence of mono- and bifunctional polymer chains in the precursor polymer P1 (see Figure S2, SI section). ${ }^{24}$ Although lipoic acid represents a bidentate ligand and has already been exploited to achieve coatings of CdSe@ZnS QDs via ligand exchange, the application of multidentate anchor groups (containing more than two anchor groups) is often desired to achieve a more stable surface coating. Therefore, we expanded 1,3-dipolar cycloaddition to azides $\mathbf{2}$ and $\mathbf{3}$ bearing two and three lipoic acid residues,

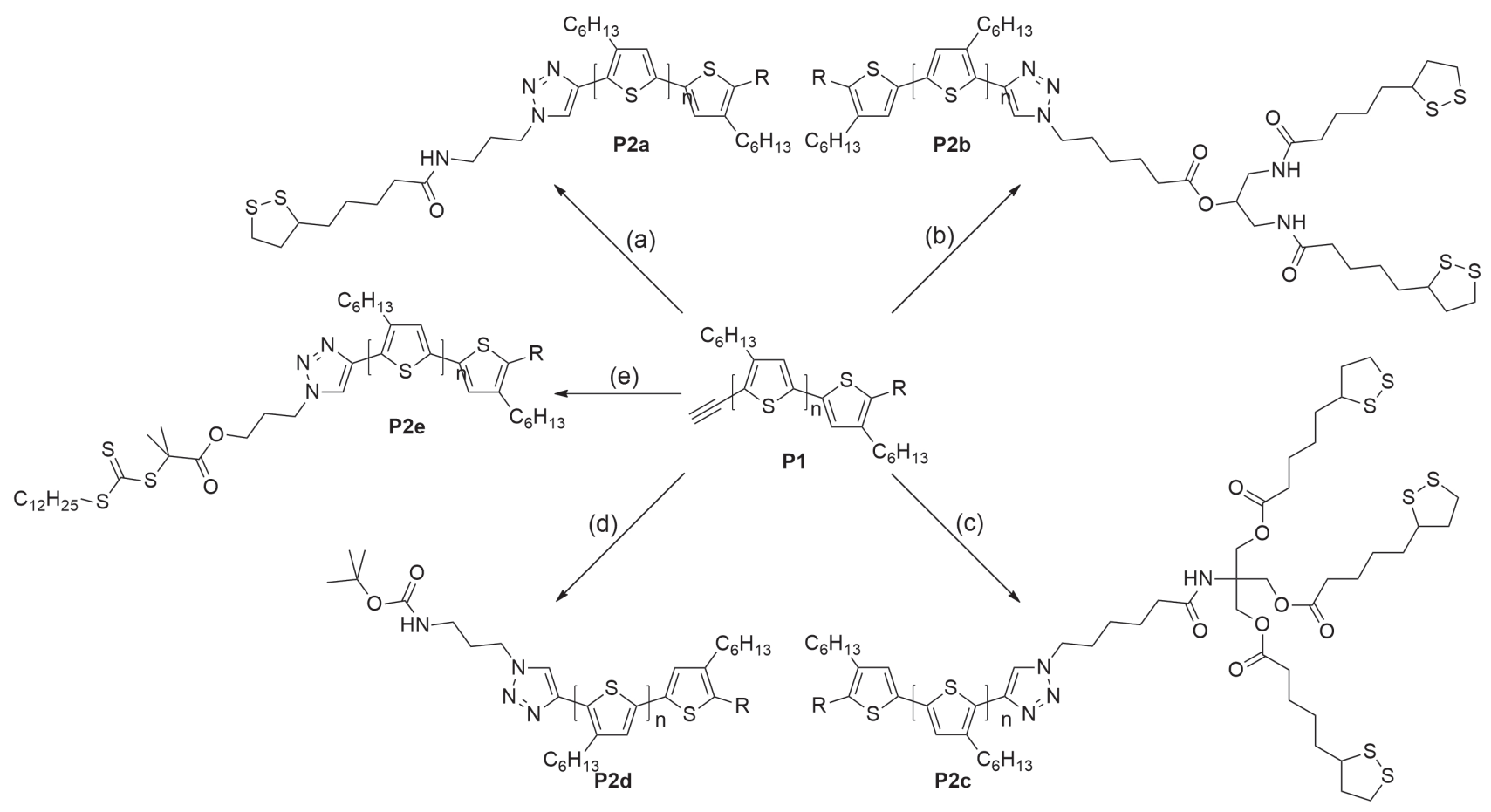

Figure 2. Incorporation of functional end groups via copper catalyzed azide-alkyne Huisgen cycloaddition using $\left[\mathrm{Cu}\left(\mathrm{NCCH}_{3}\right)_{4}\right]\left[\mathrm{PF}_{6}\right], 2$,6-lutidine and azides carrying (a) monolipoic acid (1), (b) dilipoic acid (2), (c) trilipoic acid (3), (d) Boc-protected amine (4) and (e) trithiocarbonate (5). The structures of azides 1-5 are illustrated in Figure S1, Supplementary Information section. 

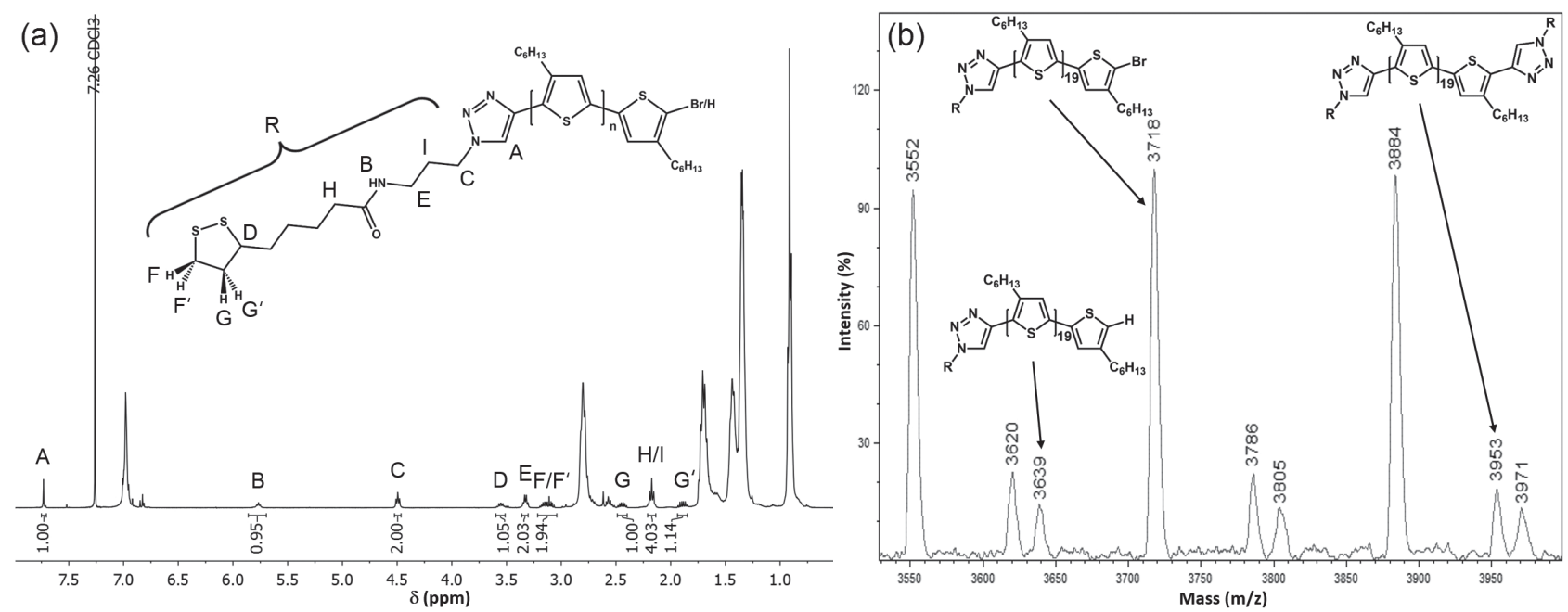

Figure 3. (a) ${ }^{1} \mathrm{H}$ NMR spectrum ( $400 \mathrm{MHz}, \mathrm{CDCl}_{3}$ ) of polymer P2a proving the successful incorporation of the lipoic acid end group; (b) MALDI-TOF mass spectrum of P2a revealing all three possible end group combinations: $\mathrm{H} /$ triazole, Br/triazole, and triazole/triazole. A magnified ${ }^{1} \mathrm{H}$ NMR spectrum and the complete MALDI-TOF mass spectrum is shown in Figures S3 and S4, Supplementary Information section.

respectively. ${ }^{20}$ Consequently, the resulting polymers $\mathbf{P 2 b}$ and P2c were equipped with tetra- and hexadentate anchor groups, respectively, and the successful incorporation of the respective end groups was verified by ${ }^{1} \mathrm{H}$ NMR spectroscopy and MALDI-TOF MS (see Figures S5 to S8, SI section).

The attachment of the multidentate anchor groups should simplify ligand exchange and thus improve the stability of the hybrid structures compared to polymer P2a. However, we found no discrepancy in ligand exchange since stable dispersions of CdSe@ZnS QDs were achieved using either P2a, P2b or P2c. In addition, the characterization of the nanocomposites via TEM revealed individually dispersed QDs in combination with small aggregates in all cases (see Figure S12, SI section). IR spectroscopy gave further evidence for the successful ligand exchange. The spectrum of the nanocomposite displayed characteristic bands of the QDs as well as the P3HT, such as the band at approximately $1545 \mathrm{~cm}^{-1}$ originating from the zinc sulfide shell of the QDs and the aromatic $\mathrm{C}=\mathrm{C}$ band at $1653 \mathrm{~cm}^{-1}$ from P3HT (see Figure S13, SI section).

To expand the scope of introducing anchor groups, we aimed at installing primary amines at the P3HT end group. Primary amines are popular anchor groups which have been applied for successful ligand exchange in many cases, and their incorporation exemplifies the versatility of the approach presented in the study at hand. In a first step, tert-butyloxycarbonyl (Boc)-protected 3-azidopropylamine (4) was installed at the polymer chain end (P2d) followed by the deprotection with trifluoroacetic acid yielding the free amine end group (P3). The end group modifications were monitored using ${ }^{1} \mathrm{H}$ NMR spectroscopy and the successful integration of the primary amine as the polymer end group was evidenced by MALDI-TOF MS (see Figure 4). Upon addition and reaction of compound 4 via 1,3-dipolar cycloaddition, the singlet of the alkyne proton (3.53 ppm) vanished while a new singlet appeared at $7.77 \mathrm{ppm}$ (in $\mathrm{CDCl}_{3}$ ) which can be assigned to the proton located at the triazole ring. The deprotection of the amine in the succeeding step was verified by the disappearance of the strong singlet at $1.45 \mathrm{ppm}$ originating from the Boc-group (see Figure 4a). Similarly to the results presented above, the MALDI-TOF mass spectrum revealed three concomitant molecular weight distributions which were assigned to the three possible end group combinations, as displayed in Figure 4b.

To further address other commonly used nanoparticles, catechol which is a well-known anchor group for metal oxides such as $\mathrm{TiO}_{2}$ or $\mathrm{Fe}_{2} \mathrm{O}_{3}$ was introduced to P3HT. ${ }^{9}$ In the case of $\mathrm{TiO}_{2}$, for example, a single catechol unit located at the polymer chain end was shown to be sufficient to achieve a stable coating. ${ }^{28}$ Caused by the interaction with unsaturated metal centers at the nanoparticle surface, catechol forms a coordination complex with a beneficial five-membered ring-geometry, which leads to a stable functionalization of $\mathrm{TiO}_{2}$ nanoparticles. ${ }^{29}$ Unfortunately, the attachment of a catechol-bearing azide via 1,3-dipolar cycloaddition has not been successful. Instead, azide 5 (Figure S1, SI section) was incorporated carrying a trithiocarbonate group. The resulting polymer P2e (Figure 5, ${ }^{1} \mathrm{H}$ NMR see Figure S14, SI section) was then used as macro-chain transfer agent (CTA) in the reversible addition-fragmentation chain-transfer (RAFT) polymerization of pentafluorophenyl 4-vinylbenzoate, since this reactive ester block is known to be responsive toward numerous aliphatic and aromatic amines. Considering the reaction with dopamine, the chemoselective reactivity of 

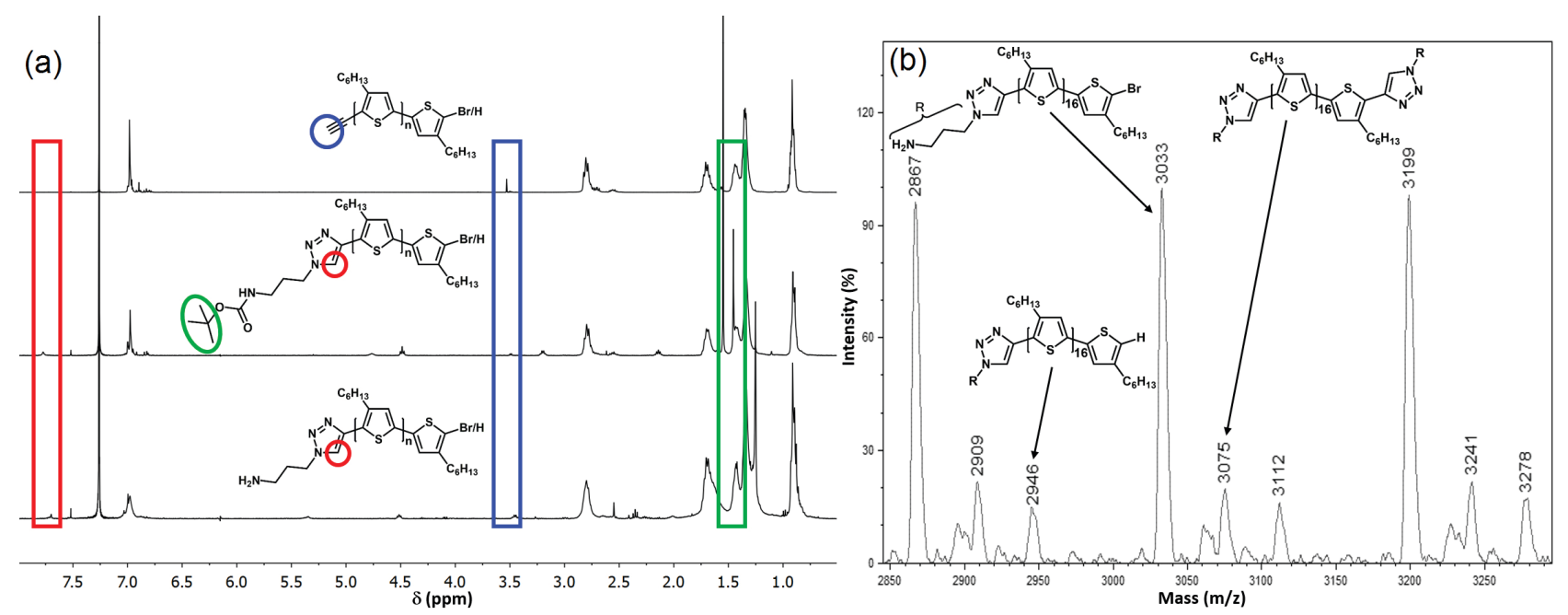

Figure 4. (a) ${ }^{1} \mathrm{H}$ NMR spectra (400 $\mathrm{MHz}, \mathrm{CDCl}_{3}$ ) monitoring the incorporation of Boc-protected 3-azidopropylamine (4) via 1,3-dipolar cycloaddition (P2d) and the synthesis of polymer $\mathbf{P 3}$ by deprotection of the amine; (b) MALDI-TOF mass spectrum of $\mathbf{P 3}$ (DP ca. 17) with assignment of the three possible end group combinations. For magnified ${ }^{1} \mathrm{H}$ NMR spectra of $\mathbf{P 2 d}$ and $\mathbf{P 3}$ and the complete MALDI-TOF mass spectrum of $\mathbf{P 3}$ see Figures S9 to S11, Supplementary Information section.

the pentafluorophenyl-ester with amines over alcohols is crucial for the successful modification. ${ }^{9,21}$ The successful synthesis of block copolymer P4a was verified by ${ }^{1} \mathrm{H}$ and ${ }^{19}$ F NMR spectroscopy (see Figures S15 and S16, SI section), when the integration of the reactive ester monomers was observed via the typically broadened monomer peaks. ${ }^{1} \mathrm{H}$ NMR spectroscopy allowed for a rough estimation of approximately five repeating units of the reactive ester block per polymer (see Figure S15, SI section). The shift in the GPC-elugram to lower elution volumes (see Figure 6a), i.e., higher hydrodynamic radii of the polymer, demonstrates the formation of the block copolymer P4a. The rather low polydispersity index (PDI) of 1.31 evidenced the controlled character of the performed polymerization.

The reaction of $\mathbf{P 4 a}$ with dopamine in the presence of triethylamine led to the formation of the catecholfunctionalized block copolymer P4b. Although only dopamine was chosen as the amine component for the post-polymerization modification, the presented reactive ester approach enables the incorporation of a broad variety of anchor groups bearing amine functionalities. ${ }^{9}$

Verifying the full conversion, the peaks of the reactive ester disappeared in the ${ }^{19} \mathrm{~F}$ NMR spectrum (see Figure S16, SI section) upon aminolysis. Additionally, IR spectroscopy proves the successful incorporation of dopamine as the significant signals of the reactive ester $\left(\mathrm{C}=\mathrm{O}\right.$ at $1760 \mathrm{~cm}^{-1}$ and $\mathrm{C}-\mathrm{F}$ at $1519 \mathrm{~cm}^{-1}$ ) vanished and a new $\mathrm{C}=\mathrm{O}$ band at $1734 \mathrm{~cm}^{-1}$ appeared corresponding to the newly formed amide bond (see Figure $6 \mathrm{~b}$ ).

Moreover, an additional shift toward higher elution volumes can be observed in the GPC, as displayed in Figure 6a. This might be explained by a lower solubility of the incorporated dopamine moiety in THF.

Finally, the introduction of dopamine allows the polymer to coordinate to inorganic metal oxide nanoparticles, as demonstrated herein for $\mathrm{TiO}_{2}$ nanoparticles. The

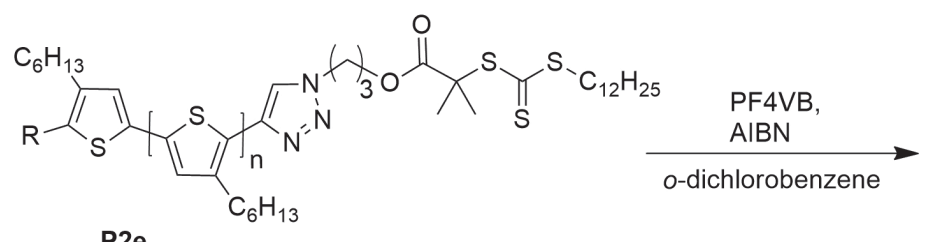

P2e

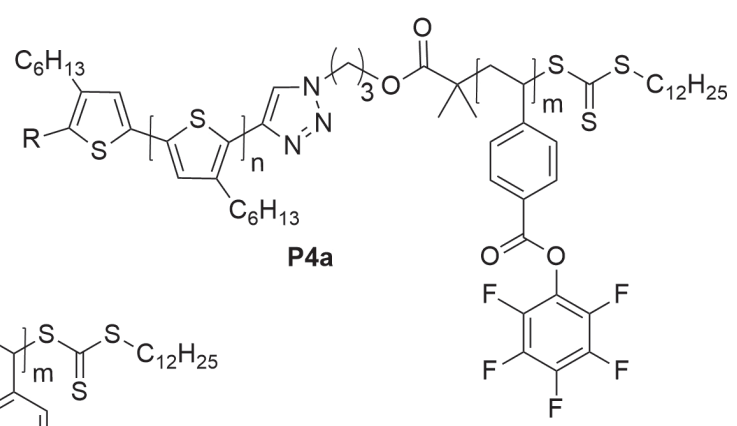

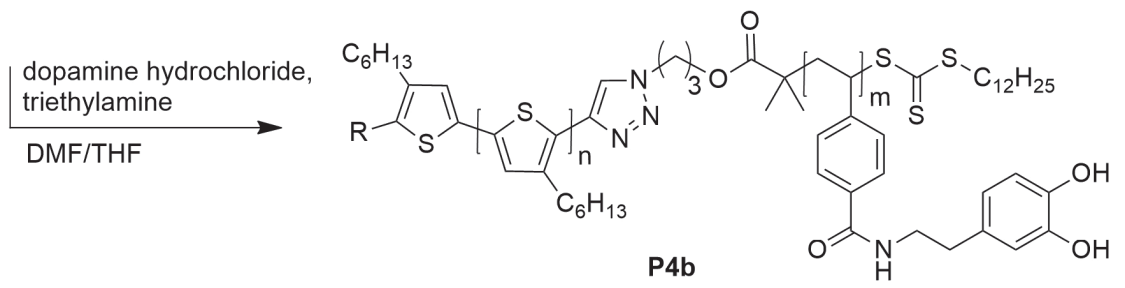

P4b

Figure 5. Synthesis scheme of P3HT containing a dopamine anchor block via a reactive ester approach. 

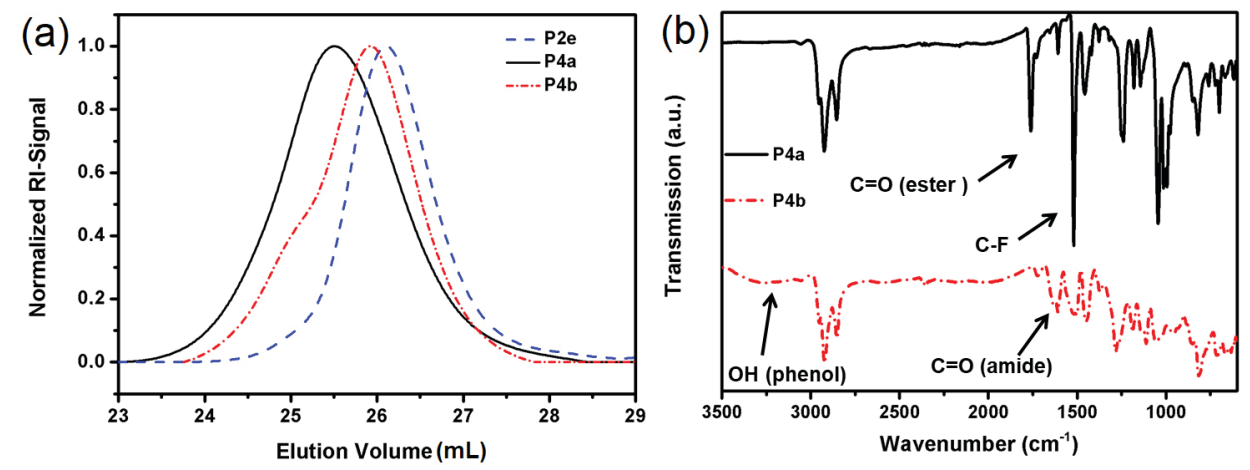

Figure 6. (a) GPC elugram of P2e (blue), P4a (black) and P4b (red); (b) FTIR (ATR) spectra of P4a (black) and P4b (red) confirming the successful aminolysis with dopamine.

functionalization of the particles resulted in dispersions which are stable for weeks. This observation is in agreement with earlier reports on polymer-coated nanoparticles., ${ }^{79-11}$ TEM measurements (Figure S17A, SI section) show individually dispersed nanoparticles in combination with rather small aggregates, whereby it is not clear if the aggregates are a result of the sample preparation process (dispersions were drop-coated onto a TEM grid and then dried) or whether the aggregates are stabilized by the presence of more than one anchor group on the polymer.

In addition, an alternative approach for the attachment of a single dopamine unit to a P3HT chain was developed. This approach (approach 2 in Figure 1) permits the selective incorporation of dopamine at the $\omega$ end group as shown in Figure 7a.

$\alpha-\mathrm{Br}-\omega-\mathrm{H}-\mathrm{P} 3 \mathrm{HT}$ (P5a) was synthesized via GRIM polymerization terminated with hydrochloric acid in methanol. The resulting polymer is known to have a high end group integrity with $\mathrm{H} / \mathrm{Br}$ terminated polymers. ${ }^{5}$

The $\omega$ end group was subsequently transformed into an aldehyde applying a Vilsmeier reaction (see Figure 7a) resulting in polymer P5b. The success of the end group modification was verified using ${ }^{1} \mathrm{H}$ NMR and IR spectroscopy displaying the typical aldehyde peak $\left(\delta=10.02 \mathrm{ppm}\right.$ in $\left.\mathrm{CDCl}_{3}\right)$ and band $\left(v(\mathrm{C}=\mathrm{O})=1649 \mathrm{~cm}^{-1}\right)$, respectively (Figure S18, SI section, and Figure 7b). In the final step, dopamine was introduced by the formation of an imine. The successful reaction was confirmed by IR spectroscopy as shown in Figure $7 \mathrm{~b}$ (disappearance of the $\mathrm{C}=\mathrm{O}$ band and appearance of $\mathrm{C}=\mathrm{N}$ band at $1617 \mathrm{~cm}^{-1}$ ) and by ${ }^{1} \mathrm{H}$ NMR spectroscopy (imine proton at $8.22 \mathrm{ppm}$ in $\mathrm{CDCl}_{3}$, see Figure S19, SI section).

The dopamine end group carrying P3HT (P5c) was again used for the functionalization of $\mathrm{TiO}_{2}$ nanoparticles via ligand exchange. The successful ligand exchange was evidenced by qualitative IR spectroscopy, as typical bands of the polymer were observed in the IR spectrum of the nanocomposite (e.g. aromatic $\mathrm{C}=\mathrm{C}$ at $1654 \mathrm{~cm}^{-1}$ and the aromatic ring vibration bands at $1453 \mathrm{~cm}^{-1}$, see Figure S20, SI section). The TEM image of the nanocomposite, presented in Figure S17B (SI section), displays well dispersed particles and, in contrast to particles coated with $\mathbf{P} \mathbf{4 b}$, no aggregates. Thus, the incorporation of dopamine as a single anchoring end group led to individually dispersed $\mathrm{TiO}_{2}$ nanoparticles avoiding the formation of aggregates, which has been observed for particles functionalized with P3HT obtained from approach 1 (see Figure 1 and Figure S17A, SI section). Finally, Figure S21 (SI section) shows thermogravimetric data of P4b- and P5c-functionalized $\mathrm{TiO}_{2}$ nanoparticles. More quantitatively, the weight loss detected for $\mathrm{TiO}_{2}$ nanoparticles functionalized with block copolymer $\mathbf{P} \mathbf{4 b}$ is (a)

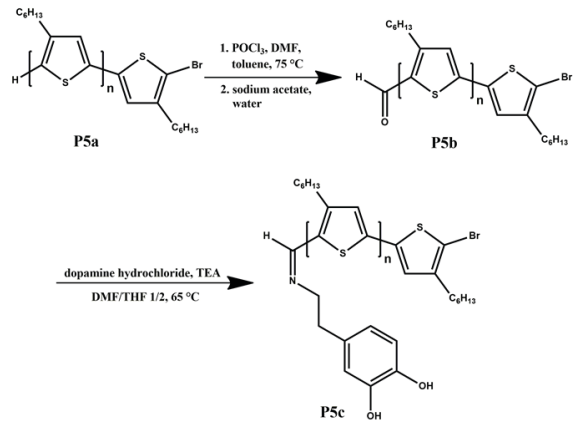

(b)

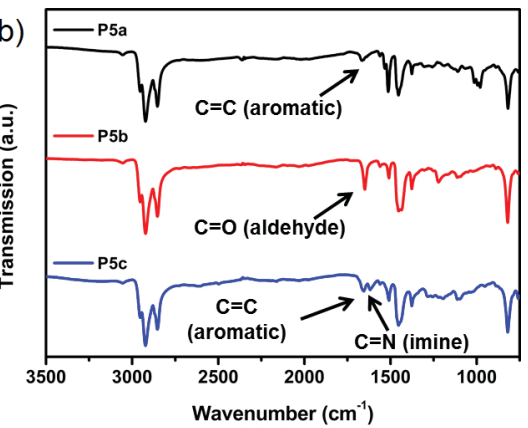

Figure 7. (a) Synthetic route for dopamine end group functionalized P3HT and (b) FTIR (ATR) spectra of P5a (black), P5b (red) and P5c (blue). 
enhanced by factor 2.2 (28 wt.\%), when compared to those prepared from mono end group functionalized P3HT P5c (12.5 wt.\%). This indicates that modified P3HT binds to $\mathrm{TiO}_{2}$ nanoparticles more efficiently, when the number of anchor groups is increased.

\section{Conclusion}

This study demonstrates the synthesis of P3HT equipped with diverse anchor groups for the functionalization of common inorganic nanoparticles. Mono- and bifunctionalized ethynyl-terminated P3HT with narrow molecular weight distributions have been synthesized via GRIM polymerization, terminated with ethynylmagnesium bromide. Afterwards, quantitative copper-catalyzed 1,3-dipolar cycloaddition of the ethynyl end groups and functional azides enabled the formation of P3HT equipped with (i) amine, (ii) mono- and multidentate disulfide and (iii) catechol anchor groups. The cycloaddition enabled the incorporation of different anchor groups into the same batch of ethynyl-terminated P3HT leading to polymers with the same optoelectronic but different anchoring properties.

Depending on the future application of nanoparticles functionalized with semiconducting polymers, different anchoring abilities of the polymer are desired. The synthetic routes presented in this study enable the versatile functionalization of $\mathrm{P} 3 \mathrm{HT}$ and enable investigations on the selective influence of anchor groups on the performance of hybrid optoelectronic devices.

\section{Supplementary Information}

NMR spectra, MALDI-TOF mass spectra, TEM images, TGA data as well as a table summarizing the polymers used in this study are available free of charge at http://jbcs.sbq.org.br as PDF file.

\section{Acknowledgments}

The authors gratefully thank the Deutsche Forschungsgemeinschaft (DFG): International Research Training Group (IRTG) 1404 "Self-Organized Materials for Optoelectronics” for funding. A. F. and B. O. would like to thank the graduate school MAINZ and are recipients of the fellowship through the Excellence Initiative (DFG/GSC 266). Furthermore, the authors want to thank Muhammad Nawaz Tahir from Johannes Gutenberg University and group of Prof Kookheon Char from the Seoul National University for providing the inorganic nanoparticles.

\section{References}

1. Moses, D.; Appl. Phys. Lett. 1992, 60, 3215; Koynov, K.; Bahtiar, A.; Ahn, T.; Cordeiro, R. M.; Hörhold, H.-H.; Bubeck, C.; Macromolecules 2006, 39, 8692; Burroughes, J. H.; Bradley, D. D. C.; Brown, A. R.; Marks, R. N.; Mackay, K.; Friend, R. H.; Burn, P. L.; Holmes, A. B.; Nature 1990, 347, 539; Sariciftci, N. S.; Smilowitz, L.; Heeger, A. J.; Wudl, F.; Science 1992, 258, 1474.

2. McCullough, R. D.; Lowe, R. D.; Jayaraman, M.; Anderson, D. L.; J. Org. Chem. 1993, 58, 904.

3. Kang, E.-H.; Lee, I. S.; Choi, T.-L.; J. Am. Chem. Soc. 2011, 133, 11904; Menk, F.; Shin, S.; Kim, K.-O.; Scherer, M.; Gehrig, D.; Laquai, F.; Choi, T.-L.; Zentel, R.; Macromolecules 2016, 49, 2085; Menk, F.; Mondeshki, M.; Dudenko, D.; Shin, S.; Schollmeyer, D.; Ceyhun, O.; Choi, T.-L.; Zentel, R.; Macromolecules 2015, 48, 7435; Yu, C.-Y.; Turner, M. L.; Angew. Chem., Int. Ed. 2006, 45, 7797.

4. Handa, N. V.; Serrano, A. V.; Robb, M. J.; Hawker, C. J.; J. Polym. Sci., Part A: Polym. Chem. 2015, 53, 831; Jeffries-EL, M.; Sauvé, G.; McCullough, R. D.; Adv. Mater. 2004, 16, 1017.

5. Iovu, M. C.; Sheina, E. E.; Gil, R. R.; McCullough, R. D.; Macromolecules 2005, 38, 8649.

6. Li, G.; Zhu, R.; Yang, Y.; Nat. Photonics 2012, 6, 153.

7. Mathias, F.; Fokina, A.; Landfester, K.; Tremel, W.; Schmid, F.; Char, K.; Zentel, R.; Macromol. Rapid Commun. 2015, 36, 959.

8. Cochin, D.; Passmann, M.; Wilbert, G.; Zentel, R.; Wischerhoff, E.; Laschewsky, A.; Macromolecules 1997, 30, 4775.

9. Zorn, M.; Meuer, S.; Tahir, M. N.; Khalavka, Y.; Sönnichsen, C.; Tremel, W.; Zentel, R.; J. Mater. Chem. 2008, 18, 3050.

10. Zorn, M.; Bae, W. K.; Kwak, J.; Lee, H.; Lee, C.; Zentel, R.; Char, K.; ACS Nano 2009, 3, 1063.

11. Meuer, S.; Oberle, P.; Theato, P.; Tremel, W.; Zentel, R.; Adv. Mater. 2007, 19, 2073.

12. Liu, J.; Tanaka, T.; Sivula, K.; Alivisatos, A. P.; Fréchet, J. M. J.; J. Am. Chem. Soc. 2004, 126, 6550.

13. Liu, Z.; Sun, Y.; Yuan, J.; Wei, H.; Huang, X.; Han, L.; Wang, W.; Wang, H.; Ma, W.; Adv. Mater. 2013, 25, 5772; Zhou, R.; Stalder, R.; Xie, D.; Cao, W.; Zheng, Y.; Yang, Y.; Plaisant, M.; Holloway, P. H.; Schanze, K. S.; Reynolds, J. R.; Xue, J.; ACS Nano 2013, 7, 4846.

14. Guzelturk, B.; Menk, F.; Philipps, K.; Kelestemur, Y.; Olutas, M.; Zentel, R.; Demir, H. V.; J. Phys. Chem. C 2016, 120, 3573.

15. Olson, J. D.; Gray, G. P.; Carter, S. A.; Sol. Energy Mater. Sol. Cells 2009, 93, 519; Knowles, K. E.; Tice, D. B.; McArthur, E. A.; Solomon, G. C.; Weiss, E. A.; J. Am. Chem. Soc. 2010, 132, 1041; Soreni-Harari, M.; Yaacobi-Gross, N.; Steiner, D.; Aharoni, A.; Banin, U.; Millo, O.; Tessler, N.; Nano Lett. 2008, 8,678 .

16. Greaney, M. J.; Brutchey, R. L.; Mater. Today 2015, 18, 31; Greenham, N. C.; Peng, X.; Alivisatos, A. P.; Phys. Rev. B 1996, 54, 17628. 
17. Chen, H.-C.; Lai, C.-W.; Wu, I.-C.; Pan, H.-R.; Chen, I.-W. P.; Peng, Y.-K.; Liu, C.-L.; Chen, C.-H.; Chou, P.-T.; Adv. Mater. 2011, 23, 5451.

18. Fokina, A.; Lee, Y.; Chang, J. H.; Park, J. H.; Sung, Y.; Bae, W. K.; Char, K.; Lee, C.; Zentel, R.; Adv. Mater. Interfaces 2016, $18,1600279$.

19. Ehlert, S.; Taheri, S. M.; Pirner, D.; Drechsler, M.; Schmidt, H.-W.; Förster, S.; ACS Nano 2014, 8, 6114.

20. Fokina, A.; Klinker, K.; Jeong, B. G.; Bae, W. K.; Barz, M.; Zentel, R.; Macromolecules 2016, 49, 3663.

21. Nilles, K.; Theato, P.; Eur. Polym. J. 2007, 43, 2901.

22. Gondi, S. R.; Vogt, A. P.; Sumerlin, B. S.; Macromolecules 2007, 40, 474; Xiao, S.; Fu, N.; Peckham, K.; Smith, B. D.; Org. Lett. 2010, 12, 140; Carboni, B.; Benalil, A.; Vaultier, M.; J. Org. Chem. 1993, 58, 3736.

23. Surin, M.; Coulembier, O.; Tran, K.; Winter, J. D.; Leclère, P.; Gerbaux, P.; Lazzaroni, R.; Dubois, P.; Org. Electron. 2010, 11,767 .
24. Jeffries-EL, M.; Sauvé, G.; McCullough, R. D.; Macromolecules 2005, 38, 10346.

25. Weymiens, W.; Hartl, F.; Lutz, M.; Slootweg, J. C.; Ehlers, A. W.; Mulder, J. R.; Lammertsma, K.; Eur. J. Org. Chem. 2012, 2012, 6711 .

26. Oschmann, B.; Bresser, D.; Tahir, M. N.; Fischer, K.; Tremel, W.; Passerini, S.; Zentel, R.; Macromol. Rapid Commun. 2013, 34, 1693.

27. Mattoussi, H.; Mauro, J. M.; Goldman, E. R.; Anderson, G. P.; Sundar, V. C.; Mikulec, F. V.; Bawendi, M. G.; J. Am. Chem. Soc. 2000, 122, 12142.

28. Mathias, F.; Tahir, M. N.; Tremel, W.; Zentel, R.; Macromol. Chem. Phys. 2014, 215, 604.

29. Rajh, T.; Chen, L. X.; Lukas, K.; Liu, T.; Thurnauer, M. C.; Tiede, D. M.; J. Phys. Chem. B 2002, 106, 10543.

Submitted: September 8, 2017 Published online: October 17, 2017 